\title{
MENSURAÇÃO DO RISCO DE UM PROJETO DE BASE IMOBILIÁRIA A PARTIR DO CASH FLOW AT RISK ${ }^{1}$ \\ RISK MEASUREMENT OF A BASE PROJECT FROM REAL ESTATE CASH FLOW AT RISK
}

\author{
Gustavo Rezler ${ }^{2}$ \\ Wesley Vieira Silva ${ }^{3}$ \\ Jansen Maia Del Corso ${ }^{4}$ \\ Luiz Carlos Duclós ${ }^{5}$
}

\begin{abstract}
RESUMO: O setor de incorporação imobiliária se aproxima cada vez mais do mercado de capitais, pela sua característica de demandar capital intensivo. Dado o fato que os prazos de maturação dos produtos imobiliários são demasiadamente longos, se abrem espaços para várias incertezas afetarem os resultados destes projetos. neste sentido, este trabalho apresenta os resultados gerados a partir da utilização da métrica cash flow at risk, para mensurar as probabilidades de perda financeira de um empreendimento de base imobiliária, na cidade de Balneário Camboriú, sc. com a utilização desta métrica os incorporadores poderão apresentar aos potenciais investidores não somente os tradicionais resultados demonstrados a partir dos cálculos utilizados em estudos de viabilidade econômico-financeira, como VPL, TIR, ROI, EVA, ROA E PAYBACK, mas, poderão mensurar os riscos de perda financeira para seus investidores e, consequentemente, gerenciar estes riscos no decorrer do projeto. ou seja, poderão verificar as variabilidades para um projeto cujos indicadores originais demonstram viabilidade econômico-financeira, com: TIR: 5,75\% a.m.; TMA: $10 \%$ ao ano; PAYBACK: $30^{\circ}$ mês do projeto; VPL: r\$ 6.099.411,00; taxa de rentabilidade (b/c): 30,42\% e; CFAR em confiabilidade estatística de 96,9\%, de cerca de r\$ 449 mil, ou próximo a 7\% dos valores originais.
\end{abstract}

PALAVRAS-CHAVE: CFaR; Incorporação imobiliária; gestão de riscos; Simulação de Monte Carlo; VPL.

ABSTRACT: The Real Estate sector approaches itself more and more of the capital market because of its characteristic of intensive capital demand. Because of the longest maturation period of the Real Estate developments there are some uncertainties around the feasibilities results of the original projects. In this sense this paper aims to present the results generated by the Cash Flow at Risk metric. The CFaR is a variation of the traditional VaR, largely used at the capital market. This metric is used in this dissertation to measure the probability of financial loss of one Real Estate Development based at the city of Balneário Camboriú. Thru the utilization of this metric the Real Estate developers will be allowed to show to the potential investors not only the traditional results generated by the feasibility analysis such as NPV, IRR, ROA, EVA and Payback but they will be also able to measure the risk of financial losses of the projects. Consequently they can manage these risks at the duration of the projects. More than that they could measure the risks of financial loss of their investors and consequently manage these risks during the project's life. Meaning they'll be able to check the variability of the project originally viable. The project's original indicators were: IRR: 5,75\% a.m.; Payback: 30th month; NPV: $R \$$ 6.099.411,00; Rentability rate $(B / C): 30,42 \%$ and $C F a R$ in statistical terms of 96,9\%, around $R \$ 449$ thousand, or nearby $7 \%$ of original $N P V$.

KEY-WORDS: CFaR; Real Estate; risk management; Simulation of Monte Carlo; NPV.

\footnotetext{
${ }^{1}$ Artigo Recebido em 31-10-2009. Revisado por pares em 26.07.2011. Recomendado em 28.07.2011 por Leomar dos Santos Editor. Publicado em 26.01.2012.

Organização Responsável pelo periódico: Universidade regional de Blumenau - FURB - www.furb.br/rn
}

\footnotetext{
${ }^{2}$ Pontifícia Universidade Católica do Paraná - PUCPR - gustavo.rezler@,volvo.com

${ }^{3}$ Pontifícia Universidade Católica do Paraná - PUCPR - wesley.vieira@pucpr.br

${ }^{4}$ Pontifícia Universidade Católica do Paraná - PUCPR - del.corso@pucpr.br

${ }^{5}$ Pontifícia Universidade Católica do Paraná - PUCPR - $\underline{\text { luiz.duclos@pucpr.br }}$
} 


\section{INTRODUÇÃO}

Bastante evoluído nos países desenvolvidos, o mercado imobiliário é peça importante no desenvolvimento sócio-econômico. Esse mercado é utilizado em larga escala como propagador de renda devido a sua característica fundamental de demandar a aplicação de mão-de-obra com qualificação não muito elevada, em sua grande maioria. Além de desenvolver um papel de cunho "assistencialista", o setor de construção civil também desempenha uma função econômica de significante relevância: gera movimentação de somas elevadas de dinheiro e a possibilidade de entes econômicos injetarem estas somas diretamente na economia. Tais "injeções" podem se dar de várias maneiras, como, por exemplo, pelos investimentos na produção imobiliária, pelos investimentos no mercado de capitais, atrelados em ativos imobiliários e até mesmo com a aquisição ou troca de um imóvel por outro.

Com as recentes aberturas de capital por parte de empresas representativas desse setor, a saber: Gafisa, Cyrella, Rossi, Company dentre outras, o mercado de construção civil deve experimentar um crescimento vertiginoso tanto na parte produtiva, quanto no quesito de ser visto como um investimento financeiro, superando o paradigma de que imóveis não representam retornos atraentes aos capitalistas. Com estas aberturas, o mercado imobiliário experimenta uma liquidez de algo mais do que R\$ 3,5 bilhões, segundo dados disponíveis na Bolsa de Valores de São Paulo (BOVESPA).

Todavia, a decisão de uma incorporadora ${ }^{6}$ de investir em um novo projeto imobiliário, apresenta-se do mesmo modo como para a indústria, uma decisão de investimento em ampliação de capacidade produtiva. Devem ser avaliados diversos aspectos inerentes ao projeto, cenário, economia local, regional e nacional, produtos concorrentes, entre outros, para que o empreendimento de base imobiliária tenha capacidade para atingir os retornos esperados.

A gestão de riscos para esse tipo de investimento é ainda mais complexa, porque além dos riscos chamados de engenharia ${ }^{7}$, existem os riscos de investimento em geral, e ainda os riscos macro ambientais e setoriais.

A intenção em estender a pesquisa sobre gestão de riscos direcionada às empresas de construção civil é, antes de qualquer coisa, fornecer aos empresários desse setor, ferramentas tecnicamente mais consistentes para a realização de seus trabalhos de planejamento financeiro e estratégico.

Embora as discussões sobre gerenciamento de riscos estejam aumentando tanto em quantidade, quanto em qualidade, parte significativa das obras trata somente de riscos financeiros e operacionais. Percebe-se pela aproximação ao tema que ainda existe muito a ser

6 Incorporadoras são as empresas que desenvolvem projetos imobiliários e os viabilizam, podendo ou não ser a empresa a construir e vender o empreendimento.

7 Riscos de engenharia são aqueles inerentes à própria obra. A Câmara Brasileira da Indústria da Construção (CBIC) entende como risco de engenharia os acidentes que resultem em destruição ou dano na construção, com ampla cobertura em despesas relativas à multiplicidade de riscos técnicos durante o período de realização do empreendimento. Já segundo o entendimento do Instituto Brasileiro de Re-seguros (IRB), este seguro (Seguro de Riscos de Engenharia) dá cobertura aos riscos decorrentes de falhas de engenharia nas suas diversas etapas. Divide-se em: Seguro Instalação e Montagem e Obras Civis em Construção e Seguro Quebra de Máquinas. 
estudado, principalmente no que tange às relações entre as organizações e seus inúmeros stakeholders. Contudo, a falta de uma disseminação de conhecimento mais amplo sobre gerenciamento de riscos, tecnicamente fundamentados e não baseada nos "achismos" fomentados pelo mercado financeiro é motivo de preocupação para os dirigentes das organizações, que tentam, a partir de planejamentos, antever e dirimir suas sucumbências.

Para a execução deste trabalho optou-se pela formulação de três cenários para o setor de construção civil brasileiro: otimista, mais provável e pessimista, não considerando as várias formas e tamanhos de empresas do segmento. Isto se dá em função dos dados coletados não separarem os resultados do setor de construção civil entre os tipos de empresas existentes.

Sendo assim, este trabalho avalia um empreendimento de base imobiliária, situado na cidade de Balneário Camboriú, no Estado de Santa Catarina. Tal projeto é desenvolvido por uma incorporadora imobiliária, curitibana, situada nesta mesma capital.

O trabalho encontra-se estruturado em cinco seções que podem ser sumarizadas como: a primeira trata da introdução do trabalho; a segunda refere-se ao referencial teórico-empírico; a terceira trata da metodologia da pesquisa; a quarta traz a apresentação e análise dos dados e a quinta refere-se as considerações finais, limitações e recomendações para a elaboração de trabalhos futuros.

\section{REFERENCIAL TEÓRICO-EMPÍRICO}

Nesta seção procura-se dar ao leitor uma visão das principais métricas de rentabilidade e riscos de um projeto de viabilidade econômico-financeira que dá suporte a essa pesquisa empírica, sendo estruturada em quatro subseções que podem ser sumarizadas da seguinte forma: a primeira subseção traz algumas considerações sobre as principais métricas de rentabilidade e riscos de um projeto; a segunda subseção traz algumas considerações sobre o risco de um investimento; a terceira subseção refere-se a gestão de riscos de um investimento e a quarta subseção trata da métrica de gerenciamento de riscos chamada de Cash Flow at Risk (CFaR).

\subsection{Métricas de Rentabilidade e Riscos}

Têm-se utilizado a Teoria de Finanças para entender a relação existente entre os benefícios e os ônus de cada investimento, sejam eles "financeiros ou reais ${ }^{8}$ ". As principais técnicas de análise de investimento que vêm sendo utilizadas mais comumente são: a Taxa Mínima de Atratividade, a Taxa Interna de Retorno, o Payback e o Valor Presente Líquido, dentre outros.

Para Souza e Clemente (2008) e Samanez (2007), os indicadores de avaliação de projetos podem ser divididos da seguinte maneira:

8 Investimentos financeiros são utilizados como os investimentos em papéis do mercado de capitais, em sua forma ampla; enquanto investimentos reais são utilizados como os investimentos efetuados em equipamentos, máquinas, instalações, ou generalizando, capacidade produtiva em seu escopo mais amplo. 
- Indicadores associados à rentabilidade: onde se encontram a Taxa Mínima de Atratividade (TMA), o Valor Presente Líquido (VPL); a Taxa Interna de Retorno; e o Índice Benefício/Custo (IBC);

- Indicadores associados à criação de valor: dentre os mais usuais encontram-se o Retorno sobre Investimento (ROI); o Retorno Operacional sobre o Ativo (ROA) e o Valor Econômico Adicionado (EVA);

- Indicadores associados ao risco do projeto: onde estão dispostos o Período de Recuperação do Investimento (Payback), o Beta Contábil e o Ponto de Fischer.

Os grupos supracitados visam tão somente identificar, analisar e selecionar as oportunidades de investimento de capital de uma organização, sendo eles extremamente associados ao se escolher as diferentes alternativas de investimentos em função dos recursos limitados disponíveis. Esses grupos de indicadores são detalhados subseqüentemente.

$\mathrm{Na}$ literatura os indicadores associados mais constantemente à rentabilidade de projetos são: a) A Taxa Mínima de Atratividade (TMA); b) O Valor Presente Líquido (VPL); c) A Taxa Interna de Retorno (TIR); e d) O Método Benefício-Custo (B/C). Já os indicadores mais comumente associados à criação de valor são: a) $O$ Retorno sobre o Investimento (ROI); b) Retorno Operacional sobre o Ativo (ROA); e c) Valor Econômico Adicionado (EVA).

Ainda se apresentam como novidade os indicadores associados aos riscos do projeto. O Método Payback: o cálculo do Payback estima o prazo em que os recursos retornam para as mãos do investidor. Uma das suas variações é o Duration, que nada mais é do que o prazo em que metade do valor investido retorna ao investidor. Não é apresentado seu cálculo por entender que ele seja apenas uma variação do Payback.

Para Souza e Clemente (2008), os indicadores citados anteriormente são úteis na avaliação dos riscos financeiros envolvidos nos projetos, se utilizados isoladamente. É possível fazer uma generalização ao assumir que também podem ser aplicado aos Empreendimentos de Base Imobiliária (EBI), tal como fazem as empresas daquele setor.

Entretanto, quanto mais próximos estiverem os indicadores de TMA e TIR, maior é o risco envolvido. Ainda segundo os autores supracitados quanto mais a Taxa Interna de Retorno do projeto se aproxima da Taxa Mínima de Atratividade, significa que o capital investido está imune aos riscos estratégicos, operacionais e outros, caso tivesse sido aplicado no mercado financeiro a valores da TMA.

Conforme as métricas clássicas de finanças, o orçamento de capital também apresenta a TIR e o Payback para a análise de projetos. Entretanto, estas métricas assumem o VPL como sendo a variável mais importante desde que acompanhada por outras, como o índice de rentabilidade e a análise de cenários.

\subsection{Aspectos Gerais Sobre o Risco de um Investimento}

Mesmo que a gestão de riscos esteja vinculada mais fortemente à gestão de riscos financeiros ou riscos advindos do mercado financeiro, é possível utilizar tal expressão para 
denominar a gestão das decisões que englobam o mercado em que se está inserido, bem como a gestão das variáveis controláveis ou não que o influenciam.

Um bom exemplo de que o termo "riscos" é utilizado para o mercado financeiro, é a definição de Bessis (1998), onde os riscos são definidos como impactos contrários à lucratividade, gerados por inúmeras fontes de incerteza. Por outro lado, assumindo a posição de que é ampla a utilização do termo, Jorion (2004) classifica os riscos que preocupam as empresas em três tipos: risco do negócio, risco estratégico e risco financeiro.

O conceito de risco utilizado atualmente é derivado da teoria das probabilidades, como indicado por Douglas (1987). Tal conceito demanda uma consideração de previsibilidades de dadas situações ou eventos por meio do conhecimento dos parâmetros de uma distribuição de probabilidades de acontecimentos futuros pela verificação de expectativas, utilizando-se métodos matemáticos (FGV, 1987).

De La Rocque e Lowenkron (2004) agregam a idéia de que os conceitos de risco adequados para uma gestão eficaz dos riscos de mercado são diferentes, dependendo do tipo da entidade sobre o qual vão ser aplicados. Jorion (2004) define seus três tipos de risco como sendo:

- riscos do negócio (business risks): riscos assumidos de maneira voluntária, para criar vantagem competitiva e agregar maior valia para a empresa e para seus acionistas;

- riscos estratégicos: são resultantes de mudanças nos cenários econômico e político;

- riscos financeiros: estão diretamente associados às possíveis perdas nos mercados de capitais.

A classificação dos conceitos sobre riscos financeiros varia entre os autores, embora haja alguma preferência pelas categorias listadas por Jorion (2004): mercado, crédito, liquidez, operacionais e legais. Para constar, estes não são a totalidade dos riscos que podem ser identificados, existindo, assim, ainda vários outros campos, como: riscos de mercado; riscos de crédito; riscos de liquidez; riscos operacionais; riscos legais; riscos de controle interno; riscos de reputação ou imagem; riscos sistêmicos; risco humano; risco de liquidação, entre outros.

Paralela àquela classificação de riscos vislumbrada por Jorion (2004), Brito (2003), De La Rocque e Lowenkron (2004) (riscos de negócio; riscos estratégicos; riscos financeiros; riscos de mercado; riscos de crédito; riscos de liquidez; riscos operacionais e riscos legais), encontra-se a definição de gestão de riscos estratégicos. Para ilustrar o que se tem de mais inovador neste campo, os riscos estratégicos, na visão de Slywotzky e Dzrik (2005), são riscos que podem ser divididos em sete grandes classes: setor, tecnologia, marca, concorrência, cliente, projeto e estagnação.

Nesse contexto, o risco difere-se de incerteza por ser justamente o ponto de corte entre o que é administrável e o que não é administrável. Para Bernstein (1997, p. 5), são freqüentes as ocasiões em que se tem julgamentos intuitivos seguros sobre a probabilidade de algum evento e se procura entender como alterá-lo com o desenrolar dos eventos reais. Enquanto a 
incerteza deleita-se ao acaso dos acontecimentos, o risco é consciente dos acontecimentos e de seus "perigos", entretanto, ele é passível de ser decidido se é ou não aceito.

\subsection{A Gestão de Riscos de um Investimento}

Bernstein (1997) defende que a origem do termo risco vem do italiano antigo risicare, que significa ousar, levando à conclusão que arriscar é uma op̧̧ão e não uma conseqüência do destino. Sendo o risco uma escolha que envolve a tomada de decisões, ele possui conseqüências importantes para a continuidade das organizações. Tais decisões devem ser baseadas em critérios coerentes e mensuráveis, o que gera a necessidade de mensuração e gestão dos riscos.

Amplamente difundida entre governos e empresas privadas há vários anos, a ação de gestão de riscos ficou conhecida por este nome principalmente após as regulamentações oferecidas pelo acordo da Basiléia em 1975. Este acordo originou-se no Banco de Compensações Internacionais - Basiléia, Suíça - a partir dos países do Grupo dos dez (G10) $)^{9}$. O Brasil faz parte desse acordo desde 1988. O grande objetivo desse acordo é "definir princípios fundamentais de supervisão bancária, adicionados de diretrizes, padrões e recomendações para a aplicação na supervisão bancária dos bancos nos países signatários", segundo o site Enciclopédia de Finanças ${ }^{10}$.

A partir dos grandes problemas financeiros causados por empresas cuja atuação era mundial, como por exemplo, Bhopal, Exxon Valdez, Enron, entre outras, vários métodos de controle de riscos, por meio de ações (operacionais, financeiras e jurídicas) começaram a ser implantados por instituições financeiras.

Voltando mais especificamente para a gestão de riscos de projetos, Damodaran (2003) defende que a gestão estratégica de risco pode afetar os fluxos de caixa futuros devido às modificações de políticas de investimentos e da criação de vantagens competitivas por parte das empresas. Tais mudanças podem impactar de maneira significativa nas taxas de crescimento e na rentabilidade dos projetos, segundo aquele autor.

De acordo com o que preconiza Slywotzky e Dzrik (2005), existe algumas ações que podem ser tomadas pelas empresas a fim de que haja uma mitigação dos riscos estratégicos que sobre elas recaem, lembrando que riscos estratégicos podem ser divididos nas grandes áreas explicadas anteriormente. Esses autores ainda defendem que este processo pode ser utilizado sozinho ou como o quarto componente de um sistema de gestão de risco empresarial, se acompanhado dos processos sobre gestão de riscos financeiros, operacionais e de acidentes.

\subsection{A Métrica Cash Flow at Risk (CFaR)}

Para a avaliação dos riscos inerentes a uma determinada empresa ou a um dado projeto, como é o caso desta pesquisa, a métrica $C F a R$ tem sido defendida por vários autores

\footnotetext{
${ }^{9}$ G-10 é a denominação para o grupo dos países mais ricos do mundo, sendo completo por: Estados Unidos (EU), Canadá, Japão, Alemanha, França, Inglaterra, Itália, Rússia, Bélgica, Holanda, Suécia e Suíça.

${ }^{10}$ Maiores informações acessar o site Enciclopédia de Finanças no endereço: http://www.enfin.com.br.
} 
como sendo uma excelente alternativa, visto sua capacidade de considerar variáveis intrínsecas à atividade da empresa, como, por exemplo, a queda nas receitas. Ver Andrén, Jankensgard e Oxelheim (2005); Perobelli (2004), De La Rocque e Lowenkron (2004), Wiedermann, Hager e Roehrl (2005).

Para Andrén, Jankensgard e Oxelheim (2005), se o VaR for aplicado em portfolios de empresas não financeiras ou sobre instrumentos financeiros como contratos de crédito, contratos de swap, contratos de câmbio, etc., ele apenas capta uma pequena parte da exposição da empresa, visto que esta forma de cálculo ignora seus fluxos de caixa operacionais.

Corroborando com o que dizem os autores supracitados, Wiedermann, Hager e Roehrl (2005) justificam que, contrariamente aos bancos, as empresas buscam horizontes mais longos para avaliação de seus projetos e empreendimentos do que os dez dias projetados pela técnica VaR. Para os empreendimentos de base imobiliária, do setor de construção civil, por exemplo, este período de análise deve ser ainda mais amplo.

Como a indústria da construção civil apresenta suas inúmeras particularidades, é interessante que seja apresentado como o comportamento citado no exemplo anterior, ao levar em consideração o projeto estudado. Para o projeto de base imobiliária têm-se as seguintes variáveis utilizadas no estudo de viabilidades desenvolvido pela própria empresa:

- variação dos preços dos insumos $=f$ (Custo Unitário Básico);

- $\quad$ variação dos preços de venda $=f($ alterações aleatórias no preço);

- variações do IVVI (Índice de Velocidade de Vendas Imobiliárias).

Desse modo, é possível determinar um número " $\mathrm{x}$ " de resultados advindos das projeções do fluxo de caixa do projeto, gerando uma tabela com esses números, a fim de que seja factível realizar a aplicação da métrica proposta.

Talvez o ponto mais interessante sobre a defesa de utilizar o $C F a R$, que é uma versão do já consolidado $V a R$, é que, tal como demonstra Securato (2002, p. 263), este método (VaR) se diferencia das medidas usuais de risco, não por medir a dispersão dos resultados (como os desvios-padrão), mas, por mensurar a probabilidade de perda financeira dos ativos individualmente.

\section{METODOLOGIA DA PESQUISA}

Os dados do projeto original de viabilidade econômico-financeira são cedidos pela empresa, conforme é explorado com mais profundidade no capítulo subseqüente. Entretanto, pode-se mencionar que o resultado das simulações dos fluxos de caixa com influência das variáveis é aplicado à métrica $C F a R$ por meio da técnica de simulação de Monte Carlo, para que seja possível extrair a variabilidade dos fluxos de caixa resultante do projeto, dadas as formulações dos cenários pretendidos. 
Para o desenvolvimento de qualquer trabalho científico é necessário um conjunto de etapas e processos a ser ultrapassado ordenadamente na investigação dos fatos ou na procura da verdade, o que para Cruz e Ribeiro (2004) se traduz em método. Seguindo-se esta linha, o método aplicado no presente trabalho é o estatístico, segundo o conceito dos autores supracitados, por que:

significa a redução de fenômenos sociológicos, políticos, econômicos, etc. em termos quantitativos. A manipulação estatística permite comprovar as relações dos fenômenos entre si, e obter generalizações sobre sua natureza, ocorrência ou significância (CRUZ; RIBEIRO, 2004).

Segundo Godoy (1995), esta pesquisa caracteriza-se como sendo quantitativa por utilizar-se, em sua maioria, de métodos matemáticos para explicar os resultados pesquisados. Nesta abordagem, valoriza-se o entendimento dos resultados matemáticos, bem como sua interpretação por parte do pesquisador.

Este trabalho trata de um estudo de caso numa empresa de construção civil do Paraná. Para Gil (1997, p. 74), o estudo de caso é caracterizado por um estudo aprofundado e exaustivo de um ou mais objetos, de maneira que se permitam a ampliação e o detalhamento dos conhecimentos daquele caso. Sua ênfase consiste na percepção do todo, havendo concentração em pontos específicos da pesquisa.

Segundo Dencker (apud CRUZ; RIBEIRO, 2004), este trabalho pode ser classificado como análise funcional por buscar as relações que os fenômenos (neste caso, as relações impulso nas variáveis) estabelecem entre si.

Com relação aos objetivos desta pesquisa, ela pode ser caracterizada como uma pesquisa explicativa, segundo o que ressalta Jung (2004, p. 153):

Esta prática visa (...) definir modelos teóricos, relacionar hipóteses em uma visão mais unitária do universo ou âmbito produtivo em geral e gerar hipóteses ou idéias por força de dedução lógica (...) a reprodução de um fenômeno, induzida em laboratório, exige modelagem e montagem de um ambiente propício (...)

Portanto, após a coleta dos dados são realizadas análises de algumas relações entre as variáveis modeladas, com as variações já impulsionadas, visando estabelecer uma análise, $a$ posteriori, da determinação dos diferentes efeitos resultantes.

Para possibilitar a construção dos cenários desejados utiliza-se o modelo matemático, que possibilita a criação de modelos abstratos de sistemas e subsistemas a serem analisados simbolicamente, conforme afirma Jung (2004, p. 69).

Também se deve caracterizar um trabalho fundamentado na aquisição de referências bibliográficas. Desta forma, a pesquisa pode ser vista como uma pesquisa bibliográfica, cujo objetivo é conhecer as diferentes contribuições científicas previamente existentes que já foram realizados acerca dos temas tratados no presente. 
Ainda, com relação ao tempo de coleta e aplicação (dimensão do tempo), este trabalho pode ser considerado como estudo de corte transversal. $O$ estudo transversal em relação ao tempo, na visão de Jung (2004, p. 164):

é aquele que se realiza em um determinado instante de tempo (t), onde a observação que irá caracterizar a situação ou mesmo qualidade do fenômeno estudado refere-se àquele exato corte temporal. Essa forma de coleta dos dados é relativamente rápida, representando apenas uma parcela da totalidade das características ou do espectro de reações do objeto de estudo.

Para o tratamento dos dados coletados são utilizadas métricas quantitativas, a fim de que se tenham resultados que corroborem com a teoria utilizada de gestão de riscos integrados. Dentre aquelas, a métrica a ser utilizada com maior intensidade para a análise dos dados e a conseqüente projeção dos resultados passíveis de comparação com seus pares de mercado é conhecida como modelo CFaR, que deriva do modelo VaR (Value at Risk).

\section{APRESENTAÇÃO E ANÁLISE DOS DADOS}

Com mais de 100 anos de atuação no segmento de incorporação imobiliária, Grupo Thá sobreviveu aos principais males que são identificados pela administração nos estudos sobre empresas familiares. Nesse mesmo período em que a empresa passava por quatro gerações de gestores membros da família, passou também, com sucesso, pelas principais crises econômicas do Brasil.

Seu histórico de atividade contempla a construção de mais de 4.000 .000 de metros quadrados para as mais variadas finalidades. Entre tais construções estão o maior shopping center da América Latina - o Shopping Dom Pedro, situado em Campinas/SP -, várias lojas de varejo, centros de distribuição, a planta da Volkswagen em São José dos Pinhais/PR, além dos incontáveis edifícios erguidos na cidade de Curitiba.

Hoje, o número estimado pela empresa para os prédios já construídos (residenciais e comerciais) é de mais de 150 obras. Passando de incorporador local a construtora nacional de obras privadas, vem demonstrando elevada capacidade de atuação nos mais diferentes setores da indústria. Esta empresa tem atuação nos seguintes Estados: Paraná; São Paulo; Santa Catarina; Rio Grande do Sul; Rio de Janeiro; Espírito Santo; Paraíba; Minas Gerais e Distrito Federal.

O empreendimento foco da pesquisa é um edifício residencial (ou de veraneio) que está sendo construídos na cidade de Balneário Camboriú, no Estado de Santa Catarina, cujo nome é Terraços da Rainha. A área total de construção deste empreendimento é de $21.784 \mathrm{~m}^{2}$, sendo que destes, apenas $17.645 \mathrm{~m}^{2}$ é área comercializável para o público em geral. Para o empreendimento são projetadas cerca de 180 unidades imobiliárias ou, simplesmente, apartamentos, cujo prazo de execução é estimado em 30 meses.

Revista de Negócios, ISSN 1980-4431, Blumenau, v16, n.3, p.79 - 95, Julho/Setembro 2011. 
Para o projeto em questão, os custos são orçados em R \$ 25.956.078,00. Certamente esse valor é estimado, tendo como base projetos semelhantes executados anteriormente e com as variações das margens de segurança técnicas.

Os 180 apartamentos expostos à venda devem gerar um valor de receitas superiores a R\$ 35 milhões. Estes valores se projetam para fazer frente aos custos da obra e a uma TMA de $10 \%$ ao ano. Originalmente, o projeto se baseia nos resultados dos indicadores usuais de análise financeira:

○ TMA: $10 \%$ ao ano;

○ TIR: $5,75 \%$ ao mês;

○ Payback: $30^{\circ}$ mês do projeto;

○ VPL: R\$ 6.099.411,00;

○ Taxa de Rentabilidade (B/C): 30,42\%

Para dirimir alguns riscos inerentes ao projeto, a empresa optou por segregar o mesmo dentro de uma Sociedade de Propósito Específico (SPE). Uma das principais vantagens desta ação é o fato de se ter o patrimônio do projeto (e de seus futuros compradores) segregado da operação da empresa.

\subsection{Os Cenários Alternativos Considerados}

O cenário mais provável - Para este caso foi mantido todas as premissas utilizadas inicialmente pela empresa, ao desenvolver seu projeto (condição ceteris paribus).

O cenário otimista - Dentro das premissas utilizadas para determinar o cenário mais provável, são alteradas as variáveis conforme encontradas a seguir, em três estágios, para que seja possível a geração de um cenário bastante otimista, mas, com uma evolução gradual:

○ Índice de velocidade de vendas é acelerado em $15 \%$;

- Preço dos insumos é reduzido $15 \%$;

○ Preço de vendas é acrescido em $15 \%$;

O cenário pessimista - Dentro das premissas utilizadas para determinar o cenário mais provável, são alteradas as variáveis conforme se encontra a seguir, para ser possível determinar cenários pessimistas para o projeto em avaliação. Esta geração, também como a otimista, é realizada em estágios para que se tenha a percepção dos níveis de "piora" a cada evolução, as quais são explicadas a seguir:

○ Índice de velocidade de vendas é diminuído em 15\%;

- Preço dos insumos é aumentado em 15\%;

○ Preço de vendas é sofre redução de $15 \%$. 
Seguindo a confecção dos cenários, foram "impulsionadas" nas variáveis de maior influência no projeto algumas variações para que produzissem efeitos no fluxo de caixa. Os resultados de todas estas simulações impulso-resposta podem ser visualizados na Figura 1 onde foram "plotados" os fluxos de caixa acumulados para todas as variações

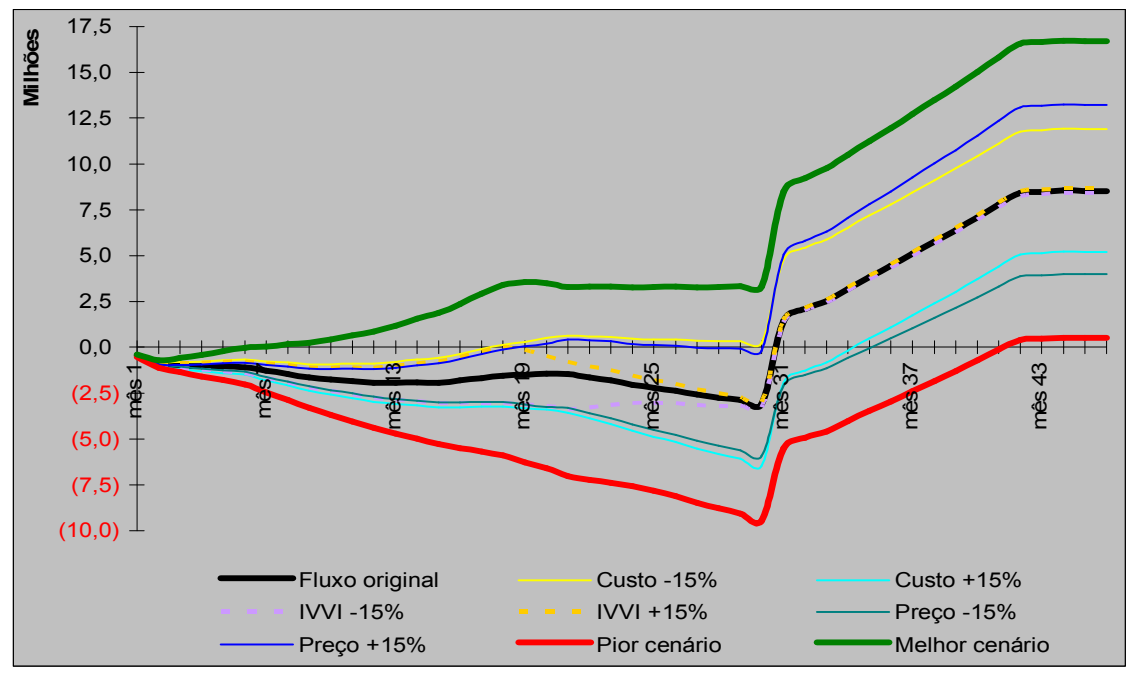

Figura 1: Fluxos de Caixa Acumulados do Projeto Analisado

\subsection{A Técnica de Simulação de Monte Carlo}

Segundo Samanez (2007) em situações nas quais não é possível dispor de equações algébricas e formulações analíticas sobre as evoluções de certos acontecimentos, é possível lançar mão de um método estatístico conhecido como Simulação de Monte Carlo (SMC) ou Método de Monte Carlo MMC. Em suma, o objetivo deste método é prover simulações do comportamento das variáveis do "acontecimento", de forma a se ter uma explicação razoável do mesmo.

Ainda de acordo com Samanez (2007), a utilização de planilhas eletrônicas e de softwares estatísticos é bastante recomendada para a execução de SMC, porque o número de testes deve ser relevante para que haja maior número de resultados, demonstrando mais fielmente o comportamento da situação.

De acordo com Lustosa, Ponte e Dominas (2004) devem ser observados alguns pontos para que se dê a correta execução do Método de Monte Carlo. A saber: a) definição das variáveis envolvidas fundamentadas em dados passados, ou em estimativas subjetivas dos gestores da organização ou do processo em análise; b) a identificação da distribuição das probabilidades geradas pelas variáveis aleatórias; c) análise das distribuições de probabilidades acumuladas para os resultados relativos às variáveis definidas; d) delimitação de intervalo dos números aleatórios do modelo; e) originar os números aleatórios e f) simular os testes do modelo formulado. 
Neste trabalho, a utilização da Simulação de Monte Carlo tem grande contribuição para a simulação das variações dos fluxos de caixa, para os vários resultados causados dentro das variações nos cenários prospectivos.

\subsection{Mensuração do VPL do Projeto de Base Imobiliária}

A variação do Valor Presente Líquido pode se apresentar bastante relevante em um projeto de base imobiliária como este. Isso pode acontecer basicamente pelas modificações passíveis de serem verificadas durante o prazo de execução da obra. A Tabela 1 mostra a real variação encontrada para o VPL utilizando-se as condições resultantes dos fluxos de caixa gerados a partir de cada cenário.

\begin{tabular}{cc} 
Tabela 1 - Valores Estimados para os VPL's do Projeto de Base Imobiliária \\
Fase & VPL [R\$] \\
\hline Fluxo original & 6.099 .411 \\
Custo $-15 \%$ & 9.049 .176 \\
\hline Custo $+15 \%$ & 3.149 .646 \\
IVVI -15\% & 5.827 .977 \\
\hline IVVI +15\% & 6.315 .225 \\
\hline Preço -15\% & 2.298 .995 \\
\hline Preço +15\% & 10.006 .013 \\
\hline TMA 15\% & 5.176 .657 \\
\hline Pior cenário (TMA 10\%) & -880.061 \\
\hline Melhor cenário (TMA 10\%) & 13.210 .262 \\
\hline Pior cenário (TMA 15\%) & -1.378 .023 \\
\hline Melhor cenário (TMA 15\%) & 11.859 .135 \\
\hline
\end{tabular}

A partir da Tabela 1 se pode perceber que, dadas certas condições de risco, como uma conjugação de vendas mais demoradas, um aumento excessivo dos preços bem como dos descontos concedidos no preço de venda, o projeto pode tornar-se desinteressante sob a ótica dessa métrica.

\subsection{Modelagem Cash Flow at Risk (CFaR)}

Seguindo a confecção dos cenários, são "impulsionadas" nas variáveis de maior influência no projeto de base imobiliária algumas variações para que produzissem efeitos no fluxo de caixa do projeto. As variáveis impulsionadas são: IVVI (Índice de velocidade de vendas), Preço de venda das unidades e Custo Total de construção do projeto. Os impulsos variam de $-15 \%$ a $+15 \%$, alternando-se os valores originais do projeto. Desta forma, criou-se para cada variável mais seis fluxos de caixa projetados, partindo-se dos resultados do fluxo de caixa original do projeto de base imobiliária.

Como uma das métricas utilizadas nessa pesquisa é o Cash Flow at Risk para um determinado empreendimento de base imobiliária, visando mensurar os seus resultados, o software Risk Solver é o que valida as projeções de risco sobre os fluxos de caixa projetado. 
Com a utilização do referido software são extraídos os resultados que embasam as conclusões de viabilidade do projeto original e, também, de alguns dos cenários alternativos. Testes estatísticos evidenciam os resultados obtidos dos valores simulados.

Para que a validade das amostras possa ser significativa em termos estatísticos, são considerados tanto os menores resultados mensais de todos os fluxos simulados, quanto os maiores valores. Com os valores mensais máximos e mínimos apresentados pela geração aleatória dos cenários são simulados 1.000 novos fluxos de caixa a partir do software Risk Solver, de onde são extraídos os resultados apresentados.

A Figura 2 demonstra que, ao considerar um nível de confiabilidade estatística de 96,9\%, têm-se a certeza de que o VPL do projeto de base imobiliária seja superior á quantia de R \$ 5.562.091,42 (cinco milhões, quinhentos e sessenta e dois mil e noventa e um reais e quarenta e dois centavos).

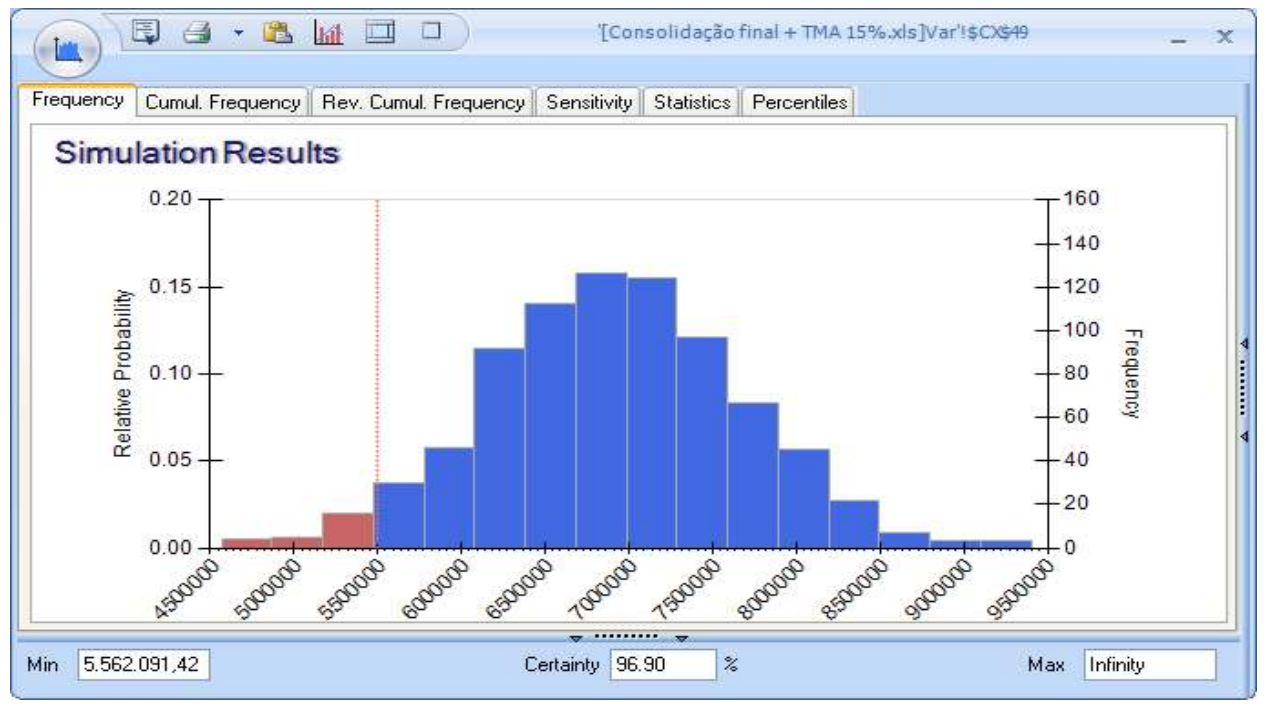

Figura 2 - Distribuição das Freqüências dos VPL's Simulados

Pautando-se na Figura 2 percebe-se que existe um risco de perda de aproximadamente de R 449 mil, frente ao valor projetado do VPL do projeto de base imobiliária. Essa variação é considerada como pequena em termos nominais se considerados os valores envolvidos no projeto de base imobiliária em questão. Todavia, a possibilidade de perda percentual é de aproximadamente $7 \%$ sobre o valor presente líquido original do projeto. Em contrapartida, a possibilidade de acréscimo aos ganhos com as projeções é extremamente significativa.

O valor estimado para a estatística qui-quadrado (valor-p) é igual a 0,0163 , sendo inferior ao nível de significância estatística de 5\%, isto é, 0,025 (bi-caudal), o que leva à aceitação da hipótese nula de que a distribuição dos fluxos de caixa sigam uma distribuição de probabilidade próxima de uma normal. 


\subsection{Mensuração e Análise do Cash Flow at Risk do Projeto de Base Imobiliária}

Para o projeto de base imobiliária em questão, após a elaboração das simulações efetuadas por meio do software Risk Solver, o valor calculado do CFaR para o projeto de base imobiliária aqui analisado é de $\mathrm{R} \$ 5.650 .666,00$ com um nível de confiança de $95 \%$. Em outras palavras, para uma projeção de VPL igual a R $6.099 .411,00$, o investidor possui 95\% de certeza de obter um retorno de, no máximo, $\mathrm{R} \$ 448.745,00$ abaixo do esperado.

Observa-se que ao tratar este número em termos percentuais, vê-se que existem aproximadamente $12,4 \%$ de perda para o investidor. A princípio, não parece que seja um número preocupante porque ainda assim o investidor tem garantido o retorno da TMA e ainda gera uma rentabilidade extra de um valor em torno dos $4,5 \%$ ao mês. Certamente a percepção de perda, neste caso, é minimizada, visto que o projeto, tanto quanto as simulações, demonstram bastante probabilidade de sucesso.

\section{CONSIDERAÇÕES FINAIS, RECOMENDAÇÕES E LIMITAÇÕES}

Empreendimentos de base imobiliária apresentaram prazos de maturação que podem variar de dois a dez anos. Em períodos de tempo desta magnitude, variáveis extrínsecas ao projeto podem mudar não apenas uma, mas, inúmeras vezes. Variáveis como taxas de câmbio, juros internacionais e nacionais, preços dos insumos, interesses da companhia, interesse dos investidores, preferências de consumos, novos concorrentes, novas tecnologias, mudança nos hábitos dos consumidores, políticas públicas, políticas ambientais, dentre outros inúmeros fatores, podem ser alterados.

Dessa maneira, considerou-se uma limitação ao presente trabalho não apenas o fato da existência destas complexidades, mas também o fato de que não foram feitos maiores estudos sobre as possíveis variações nas relações existentes no entorno do projeto aqui exposto. Como contrapontos foram avaliados os resultados do fluxo de caixa do projeto levando em consideração três das mais importantes variações que afetariam qualquer EBI: preços dos insumos, velocidade de vendas do projeto e custos dos insumos.

Dentro do contexto de tratamento do mercado imobiliário, como uma alternativa de investimento, este trabalho está limitado a aplicar a métrica proposta e verificar se ela é adequada para mensurar riscos de perda financeira para projetos desta natureza. Outra limitação deste trabalho refere-se à utilização de valores simulados em laboratório, sobre as variabilidades do fluxo de caixa original do projeto.

Com o objetivo de finalizar o trabalho, esta seção propõe-se a juntar as principais idéias originais aos resultados da aplicação das simulações matemáticas e, agregando conhecimento científico, concluir o que fora percebido durante o seu desenvolvimento.

Como as propostas deste trabalho foram, em termos gerais e específicos, testar a validade da métrica Cash Flow at Risk para um determinado empreendimento de base imobiliária e mensurar os resultados sob a ótica do investidor, acredita-se que tenha sido alcançado o objetivo. Isto se deu em função dos indicadores de rentabilidade, principalmente o VPL e a TIR, demonstram resultados favoráveis ao projeto, sob a ótica do investidor. 
Dentro dos padrões conceituais que foram admitidos neste trabalho, como risco de perdas de valores financeiros, a partir da variabilidade dos resultados do fluxo de caixa, conclui-se que, do seu valor original (VPL) de R\$ 6.099.411,00. E com o risco de perda estimado com significância de 5\%, verificou-se uma perda provável de até $\mathrm{R} \$ 448.745,00$ (quatrocentos e quarenta e oito mil e setecentos e quarenta e cinco reais). Em termos absolutos o valor foi expressivo, por se tratar de quase meio milhão de reais, o que é uma vultosa soma de dinheiro. Porém, em termos relativos seriam pouco mais de $7 \%$ de perda em um projeto com maturação total de 44 meses, que é o prazo total de recebimentos das vendas.

Dadas às possibilidades de variação de qualquer projeto de construção civil, haja vista todas as variáveis às quais está exposto, uma variação negativa no resultado final em cerca de $7 \%$ é aceitável, desde que ele ainda fosse altamente favorável economicamente. Certamente qualquer investidor que optasse por aceitar riscos em sua carteira de investimentos teria necessariamente que ter parâmetros de perda, com relação a outras alternativas disponíveis. Se for comparada com qualquer investimento em ações (alternativas de elevado grau de risco), uma certeza de $95 \%$ de que seu resultado poderia ser diminuído em, no máximo $7 \%$, como demonstrados nos 1.000 testes realizados pelo programa utilizado, certamente deporiam a favor de captar o dinheiro para este projeto imobiliário.

Entretanto, ter um retorno final em torno de 5,75\% acima da TMA é um excelente investimento, ao saber que a TMA é de $10 \%$ ao ano e que os títulos do governo pagam atualmente um valor aproximado de $12 \%$ ao ano de retorno, com sérias possibilidades de redução da taxa básica de juros paga pelo governo.

Em contrapartida, para confirmar ainda mais esta alternativa como interessante aos olhos dos investidores, a possibilidade de ter um ganho de $4,25 \%$ superior ao do projeto original, será sempre aceita. Ainda nesta linha de avaliação, vale salientar que uma taxa interna de retorno de 5,75\% ao mês foi considerada atrativa em qualquer situação, desde que fossem minimizadas as perdas possíveis a partir de cálculos estatísticos, como os utilizados nesta pesquisa.

Em se tratando de investimento imobiliário e tendo todas as deficiências técnicas apresentadas na literatura contra a utilização do indicador TIR (taxa interna de retorno), esse mercado ainda a utiliza. Dentro desta situação, os resultados apresentados referendaram ainda mais o projeto em questão.

Cabe destacar que uma confiabilidade de aproximadamente $96 \%$ de certeza, o projeto resulta em uma TIR a ser medida entre $4 \%$ e $9 \%$ de retorno ao mês para o investidor. Estes valores foram, certamente, bastante atrativos em se tratando de alternativas de investimento financeiro.

Como recomendação para realização de pesquisas futuras, outros autores podem realizar estudos utilizando-se as mesmas métricas, mas, servindo-se das séries históricas ou dados longitudinais. Isto se destinaria a avaliar a capacidade apresentada pelo modelo de captar as reais distorções nos resultados calculados, acompanhando o projeto desde a sua concepção até sua plena maturação.

Ainda, como recomendação final se indica a utilização de um modelo de mensuração de risco de fluxo de caixa, baseado na integração da utilização das métricas do $C F a R$ 
contrastando com o VPL e com a TIR do projeto em questão, a fim de que hajam argumentos mais eficazes de mensuração de riscos de perda e credibilidade do "vendedor" do projeto, frente aos investidores. Desta maneira, o setor de incorporação imobiliária apresentaria, além de excelentes rentabilidades históricas, uma profissionalização importante.

\section{REFERÊNCIAS}

ANDRÉN, Niclas; JANKENSGARD, Hakan; OXELHEIM, Lars. Exposure-based cashflow-at-risk under macroeconomic uncertainty. The Research Institute of Industrial Economics, Sweden: 2005.

BERNSTEIN, Peter L. Desafio aos Deuses: a fascinante história do risco. Rio de Janeiro: Campus, 1997.

BESSIS, J. Risk Management in Banking, $1^{\text {st }}$ Edition. John Wiley \& Sons Ltd., United Kingdom, 1998.

BRITO, Osias Santana de. Controladoria de risco - retorno em instituições financeiras. São Paulo: Saraiva, 2003.

Câmara Brasileira da Indústria da Construção. Disponível em: <http://www.cbic.org.br/>. Acesso em 07 maio 2006.

CRUZ, Carla; RIBEIRO, Uirá. Metodologia científica: teoria e prática. 2 ed. Rio de Janeiro: Axcel, 2004.

DAMODARAN, A. Value and Risk: Beyond Betas. New York: Stern School of Business, 2003.

DE LA ROCQUE, Eduarda; LOWENKRON, Alexandre (2004). Métricas e particularidades da gestão de riscos em corporações. Disponível em: $<$ http://www.listaderiscos.com.br/ll/portal/DesktopDefault.aspx?TabID=3714>,. Acesso em 08 abr. 2006.

DOUGLAS, M. Les études de perception du risque: un État de L'Art. in: Fabiani, J-L. et THEYS, J. (orgs). La Société Vulnérable Évaluer et Maîtriser les Risques. Paris: Presses de L'École Normale Supérieure, 1987, pp. 55-60.

FUNDAÇÃO GETÚlIO VARGAS (FGV). Dicionário de ciências sociais. Rio de Janeiro: FGV, 1987. (2 Volumes).

GIL, Antonio Carlos. Métodos e téenicas de pesquisa social. São Paulo: Atlas, 1997.

GODOY, Livio Antonio. Terceirização: uma abordagem estratégica. São Paulo: Pioneira, 1995.

JORION, Philippe; EBRARY, Inc. Value-at-risk: the new benchmark for managing financial risk. $2^{\text {a. }}$ Ed., New York: McGraw-Hill, 2004. 
JUNG, C. F. Metodologia para pesquisa e desenvolvimento. Rio de Janeiro: Axcel, 2004.

LUSTOSA, P. R. B., PONTE, V. M. R. e DOMINAS, W. R. Simulação. In CORRAR, L. J., THEÓPHILO, C. R. (Coord.). Pesquisa operacional para decisão em contabilidade e administração: contabilometria. São Paulo: Atlas, 2004.

MINAYO, M. C. De Souza. Ciências técnica e arte: O desafio da pesquisa social. In: (org.) Pesquisa social. $6^{\text {a }}$ Ed. Rio de Janeiro: Vozes, 1996.

PEROBELLI, Fernanda Finotti Cordeiro. Um modelo para gerenciamento de riscos em instituições não financeiras: aplicação ao setor de energia elétrica no Brasil. Tese de Doutorado, USP: São Paulo, 2004.

SAMANEZ, Carlos P. Gestão de investimentos e geração de valor. São Paulo: Pearson Prentice Hall, 2007.

SOUZA, Alceu; CLEMENTE, Ademir. Decisões financeiras e análise de investimentos: fundamentos, técnicas e aplicações. 6. ed., São Paulo: Atlas, 2008.

SLYWOTZKY, Adrian; DZRIK, John. Contra-atacando o maior de todos os riscos. Harvard Business Review. USA: Harvard University, p. 56-66, Abr., 2005.

WIEDERMANN, Arnd; HAGER, Peter; ROEHRL, Admin. Integrated risk management with cash-flow-at-risk/earnings-at-risk method. Germany: 2005. Disponível em: www.risknet.de. Acesso em: 21 jun. 2006. 